\section{Commentary: Missing the mark but we must keep trying}

\author{
Thin X. Vo, MD, MSc, and \\ Fraser D. Rubens, MD, MSc, FACS, FRCSC
}

Decision-making regarding aortic valve prosthesis and method of implantation at the time of aortic valve replacement (AVR) has become increasingly complex and requires the consideration of many factors. One area that remains unclear is the long-term rate of coronary revascularization after AVR and how this may influence the selection of interventions.

In this issue of JTCVS Open, Celik and colleagues ${ }^{1}$ help illuminate the rate of coronary revascularization after surgical AVR in patients without significant coronary stenosis at time of intervention. In their retrospective cohort study of 420 patients, they found a cumulative revascularization rate of $6.9 \%$ at 20 years, with percutaneous coronary intervention being the most common intervention $(64 \%)$. The authors suggest that these results may help provide an approximation of the long-term revascularization rate after transcatheter aortic valve implantation.

The authors should be commended for offering insight on an area of limited knowledge. The cumulative revascularization rate over a period of 20 years appears to be quite low. Furthermore, a majority of these patients only required revascularization for single-vessel disease and in nonurgent fashion, suggesting that the burden of coronary disease in these patients remains low over 2 decades.

These results, however, should be interpreted with caution. The first concern is the high rate of loss to

\footnotetext{
From the Division of Cardiac Surgery, University of Ottawa Heart Institute, Ottawa, Ontario, Canada.

Disclosures: The authors reported no conflicts of interest.

The Journal policy requires editors and reviewers to disclose conflicts of interest and to decline handling or reviewing manuscripts for which they may have a conflict of interest. The editors and reviewers of this article have no conflicts of interest.

Received for publication May 25, 2020; revisions received May 25, 2020; accepted for publication May 28, 2020; available ahead of print June 23, 2020.

Address for reprints: Fraser D. Rubens, MD, MSc, FACS, FRCSC, University of Ottawa Heart Institute, 40 Ruskin St, Ottawa, Ontario K1Y 4W7, Canada (E-mail: FRubens@ottawaheart.ca)

JTCVS Open 2020;3:102-3

2666-2736

Copyright (c) 2020 The Authors. Published by Elsevier Inc. on behalf of The American Association for Thoracic Surgery. This is an open access article under the CC BY-NCND license (http://creativecommons.org/licenses/by-nc-nd/4.0/).

https://doi.org/10.1016/j.xjon.2020.05.012
}

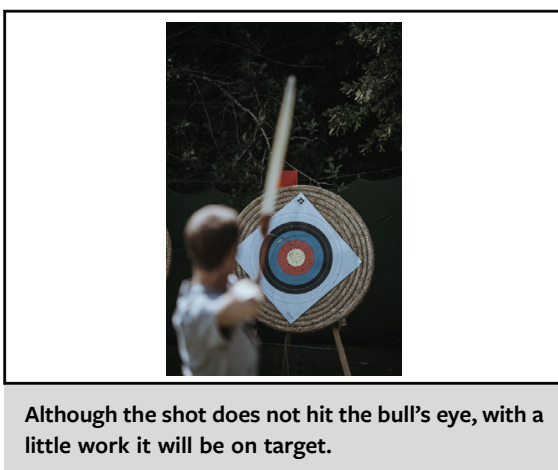

\author{
CENTRAL MESSAGE \\ The rate of revascularization af- \\ ter aortic valve intervention is \\ unclear. Further insight will assist \\ with heart team planning, espe- \\ cially in the era of emerging \\ transcatheter therapies.
}

follow-up. Of the 2256 potentially eligible patients, only 420 were included, which probably underestimates the burden of coronary artery disease faced by this patient population. ${ }^{2}$ This is important, as there was a significant discrepancy between the 2 groups. Nonfollowed patients were older, with more frequent degenerative tricuspid aortic valve disease (as opposed to the greater rate of bicuspid aortic valve disease in the followed group), factors that are likely related to the outcome of revascularization. Therefore, the patient population in the study of Celik and colleagues likely does not accurately reflect even the low-risk transcatheter aortic valve implantation population. ${ }^{3}$ From a statistical standpoint, we are also sympathetic that due to the small sample size, the primary outcome (time-to-first revascularization event) was infrequent ( 24 events) and thus the analysis may not be as credible. Likely, only 2 covariate predictors could be reliably identified without overfitting. Lastly, we would caution that there are also limitations to identifying the impact of covariates with the technique of competing risks that the authors chose. This strategy works well in predicting outcomes, but it does not accurately identify the role of predictors. Nonetheless, their data do provide some reassurance that in the younger patient population requiring aortic intervention, the likelihood of requiring surgery for bypass grafting in the future is probably on the lower side. In fact, the chance of requiring reintervention for the aortic valve over a period of 2 decades is likely greater, especially for bioprosthetic valves. ${ }^{4,5}$ 
Although they miss the bull's eye, Celik and colleagues do point us in the right direction and give the heart team data to consider as we embark toward the new age of aortic valve intervention.

\section{References}

1. Celik M, Durko AP, Head SJ, Mahtab EAF, van Mieghem NM, Cummins PA, et al. Coronary revascularization after surgical aortic valve replacement. J Thorac Cardiovasc Surg Open. 2020;3:91-101.
2. Vilalta V, Asmarats L, Ferreira-Neto AN, Maes F, de Freitas Campos Guimarães L, Couture T, et al. Incidence, clinical characteristics, and impact of acute coronary syndrome following transcatheter aortic valve replacement. JACC Cardiovasc Interv. 2018;11:2523-33.

3. Mack MJ, Leon MB, Thourani VH, Makkar R, Kodali SK, Russo M, et al. Transcatheter aortic-valve replacement with a balloon-expandable valve in low-risk patients. N Engl J Med. 2019;380:1695-705.

4. Ruel M, Kulik A, Rubens FD, Bédard P, Masters RG, Pipe AL, et al. Late incidence and determinants of reoperation in patients with prosthetic heart valves. Eur J Cardiothorac Surg. 2004;25:364-70.

5. Head SJ, Çelik M, Kappetein AP. Mechanical versus bioprosthetic aortic valve replacement. Eur Heart J. 2017;38:2183-91. 